$6^{\text {th }}$ International Conference on Hydroinformatics - Liong, Phoon \& Babovic (eds)

(C) 2004 World Scientific Publishing Company, ISBN 981-238-787-0

\title{
UNCERTAINTY IN FUZZY MEMBERSHIP FUNCTIONS FOR A RIVER WATER QUALITY MANAGEMENT PROBLEM
}

\author{
SUBHANKAR KARMAKAR \\ Research Student, Department of Civil Engineering, Indian Institute of Science, \\ Bangalore - 560 012, India \\ P. P. MUJUMDAR \\ Associate Professor, Department of Civil Engineering, Indian Institute of Science, \\ Bangalore - 560 012, India
}

Uncertainty associated with fuzzy membership functions for a water quality management problem is addressed through interval grey numbers. The lower and upper bounds of the membership functions are expressed as interval grey numbers, and the membership functions are modeled as imprecise membership functions. A grey fuzzy optimization model for water quality management of a river system is developed. Application of the optimization model with imprecise membership functions is illustrated with a hypothetical river system.

\section{INTRODUCTION}

A Waste Load Allocation (WLA) model, in general, integrates a water quality simulation model with an optimization model to provide best compromise solutions acceptable to both PCA and dischargers. Uncertainty due to imprecision in goals and model parameters in general has been addressed earlier with fuzzy sets. Sasikumar and Mujumdar (1998) [1] developed a Fuzzy Waste Load Allocation Model (FWLAM) for water quality management of a river system. A useful feature of FWLAM is its capability to incorporate the conflicting and imprecise goals of Pollution Control Agency (PCA) and dischargers in a fuzzy optimization framework. A major limitation in FWLAM is that the lower and upper bounds of the membership functions (membership parameters) are assumed fixed. As the model results are likely to vary considerably with change in the membership functions, uncertainty in the bounds and shape of the membership functions should be addressed in fuzzy optimization models for water quality management. The present work is aimed at relaxing the lower and upper bounds of the membership functions by treating them as interval grey numbers [2, 3, 4], thus providing a range of "best compromise" solutions to impart more flexibility in water quality management decisions. The Grey Fuzzy Waste Load Allocation Model (GFWLAM) [5] described in the present work, is a more flexible form of FWLAM developed earlier, and uses the concepts of grey programming [2, 4], interval analysis [3] and interval programming [6]. Optimal values of the objective function and decision variables are obtained in the form of interval grey numbers, enhancing flexibility in decision making. 


\section{GREY FUZZY WASTE LOAD ALLOCATION MODEL (GFWLAM)}

The FWLAM developed earlier, forms the basis for the optimization model developed in the present work. The system consists of a set of dischargers, who are allowed to release pollutants into the river after removing some fraction of the pollutants. Goals of the PCA and dischargers are expressed as fuzzy goals. The fuzzy membership functions themselves being imprecisely stated. A terminology "imprecise membership function" is used to represent the membership functions with uncertain membership parameters [5]. The uncertainty in membership parameters is addressed by using interval grey numbers. An interval grey number $\left(\mathrm{x}^{ \pm}\right)$is defined as an interval with known lower $\left(\mathrm{x}^{-}\right)$and upper $\left(\mathrm{x}^{+}\right)$bounds but unknown distribution information for $\mathrm{x}[4]$.

$\mathrm{x}^{ \pm}=\left[\mathrm{x}^{-}, \mathrm{x}^{+}\right]=\left[\mathrm{t} \in \mathrm{x} \mid \mathrm{x}^{-} \leq \mathrm{t} \leq \mathrm{x}^{+}\right]$

$\mathrm{x}^{ \pm}$becomes a "deterministic number" or "white number" when, $\mathrm{x}^{ \pm}=\mathrm{x}^{-}=\mathrm{x}^{+}$. Two sets of imprecisely defined and conflicting goals (i.e., goals of PCA and dischargers) are addressed through an optimization model by using interval grey numbers.

\section{Grey fuzzy goals for water quality management}

\section{Goals of PCA}

The PCA sets the desirable concentration level $\left(\mathrm{c}^{\mathrm{D}}{ }_{\mathrm{jl}}\right)$ and maximum permissible concentration level $\left(\mathrm{c}_{\mathrm{jl}}^{\mathrm{H}}\right)$ of the water quality indicator $\mathrm{j}$ (e.g., DO-deficit, hardness, nitrate-nitrogen concentration) at the water quality checkpoint $\mathrm{l}\left(\mathrm{C}_{\mathrm{jl}}^{\mathrm{D}} \leq \mathrm{c}^{\mathrm{H}}{ }_{\mathrm{j} 1}\right)$. The goal of the PCA $\left(E_{j l}\right)$ is to make the concentration level $\left(c_{j l}\right)$ of water quality indicator $j$ at the checkpoint $\mathrm{l}$ as close as possible to the desirable level, $\mathrm{C}_{\mathrm{j}}^{\mathrm{D}}$, so that the water quality at the checkpoint $l$ is enhanced with respect to the water quality indicator $j$, for all $j$ and $l$. This goal is represented by a membership function. For example, if DO-deficit is the water quality indicator, a non-increasing membership function suitably reflects goals of the PCA with respect to DO-deficit at a checkpoint. The uncertainty associated with membership parameters $\left(\mathrm{C}_{\mathrm{jl}}^{\mathrm{D}}\right.$ and $\left.\mathrm{C}_{\mathrm{jl}}^{\mathrm{H}}\right)$ is addressed using interval grey numbers, and the membership parameters are expressed as $\mathrm{c}^{\mathrm{D}}{ }_{\mathrm{jl}}$ and $\mathrm{c}^{\mathrm{H}+}{ }_{\mathrm{j} l \text {. }}$. Using non-increasing imprecise membership functions, the grey fuzzy goals of PCA are expressed as:

$$
\mu_{\mathrm{E}_{j 1}^{ \pm}}^{ \pm}\left(C_{j 1}^{ \pm}\right)= \begin{cases}1 & C_{j 1}^{+}<C_{j 1}^{D^{D-}} \\ {\left[\left(C_{j 1}^{\mathrm{H} \pm}-C_{j 1}^{ \pm}\right) /\left(C_{j 1}^{H \pm}-C_{j 1}^{\mathrm{D} \pm}\right)\right]^{\alpha_{j 1}}} & C_{j 1}^{\mathrm{D} \pm} \leq C_{j 1}^{ \pm} \leq C_{j 1}^{H \pm} \\ 0 & C_{j 1}^{-}>C_{j 1}^{H+}\end{cases}
$$

The exponent $\alpha_{\mathrm{jl}}$ is nonzero positive real number. Assignment of numerical value to this exponent is subject to the desired shape of the membership functions. A value of $\alpha_{j 1}=1$ leads to linear imprecise membership function. 
Goals of dischargers

The grey fuzzy goals of the dischargers are similarly expressed as:

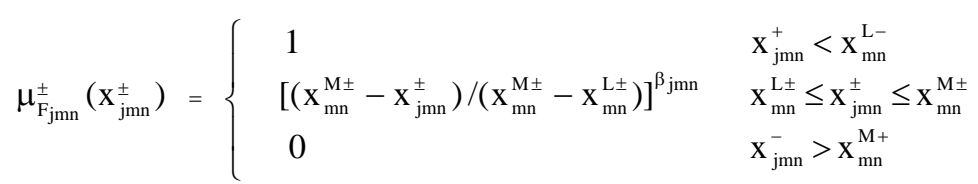

where the aspiration level and maximum acceptable level of fractional removal of the pollutant $\mathrm{n}$ at discharger $\mathrm{m}$ are represented as $\mathrm{x}_{\mathrm{mn}}^{\mathrm{L}}$ and $\mathrm{x}^{\mathrm{M}}{ }_{\mathrm{mn}}$, respectively $\left(\mathrm{x}_{\mathrm{mn}}^{\mathrm{L}} \leq \mathrm{x}^{\mathrm{M}}{ }_{\mathrm{mn}}\right)$. Similar to the exponent $\alpha_{j l}$ in Eq. (2), $\beta_{\text {jmn }}$ is nonzero positive real number. The goal of the dischargers $\left(\mathrm{F}_{\mathrm{jmn}}\right)$ is to make the fractional removal level $\left(\mathrm{x}_{\mathrm{jmn}}\right)$ as close as possible to $\mathrm{x}^{\mathrm{L}}{ }_{\mathrm{m}}$, to minimize the waste treatment cost for pollutant $\mathrm{n}$. These two sets of conflicting and imprecise goals are incorporated in the optimization model using "fuzzy decision" concept proposed by Bellman and Zadeh [7].

\section{Formulation}

GFWLAM is represented as:

$\operatorname{Max} \lambda^{ \pm}$

subject to

$$
\begin{array}{rlrl}
\mu_{\mathrm{E}_{\mathrm{jl}}}^{ \pm}\left(\mathrm{c}_{\mathrm{jl}}^{ \pm}\right)=\left[\left(\mathrm{c}_{\mathrm{jl}}^{\mathrm{H} \pm}-\mathrm{c}_{\mathrm{jl}}^{ \pm}\right) /\left(\mathrm{c}_{\mathrm{jl}}^{\mathrm{H} \pm}-\mathrm{c}_{\mathrm{jl}}^{\mathrm{D} \pm}\right)\right]^{\alpha_{\mathrm{jl}}} \geq \lambda^{ \pm} & & \forall \mathrm{j}, \mathrm{l} \\
\mu_{\mathrm{F}_{\mathrm{jmn}}}^{ \pm}\left(\mathrm{x}_{\mathrm{jmn}}^{ \pm}\right)=\left[\left(\mathrm{x}_{\mathrm{mn}}^{\mathrm{M} \pm}-\mathrm{x}_{\mathrm{jmn}}^{ \pm}\right) /\left(\mathrm{x}_{\mathrm{mn}}^{\mathrm{M} \pm}-\mathrm{x}_{\mathrm{mn}}^{\mathrm{L} \pm}\right)\right]^{\beta_{\mathrm{jmn}}} \geq \lambda^{ \pm} & \forall \mathrm{j}, \mathrm{m}, \mathrm{n} \\
\mathrm{c}_{\mathrm{jl}}^{\mathrm{D} \pm} \leq \mathrm{c}_{\mathrm{jl}}^{ \pm} \leq \mathrm{c}_{\mathrm{j} 1}^{\mathrm{H} \pm} & \forall \mathrm{j}, \mathrm{l} \\
\mathrm{x}_{\mathrm{mn}}^{\mathrm{L} \pm} \leq \mathrm{x}_{\mathrm{jmn}}^{ \pm} \leq \mathrm{x}_{\mathrm{mn}}^{\mathrm{M} \pm} & \forall \mathrm{j}, \mathrm{m}, \mathrm{n} \\
0 \leq \lambda^{ \pm} \leq 1 &
\end{array}
$$

The constraints (5) and (6) are constructed from membership functions for the goals of PCA and dischargers, respectively. These constraints define the minimum goal fulfillment level $\left(\lambda^{ \pm}\right)$. The crisp constraints (7) and (8) are based on the water quality requirements set by the PCA, and possible fractional removal levels by the dischargers, respectively. Constraint (9) represents the bounds on the parameter $\lambda^{ \pm}$.

In the expression for goals of PCA [constraint (5)], the concentration level $\mathrm{c}^{ \pm}{ }_{\mathrm{j}}$, of water quality indicator $\mathrm{j}$ at checkpoint $\mathrm{l}$, may be mathematically expressed as:

$c_{j 1}^{ \pm}=f\left(x_{j m n}^{ \pm}\right)$

where the transfer function $\mathrm{f}$ indicates the aggregated effect of all pollutants and dischargers (located upstream of checkpoint 1 ) on the water quality indicator $\mathrm{j}$. The 
transfer function can be evaluated using appropriate mathematical models that determine spatial distribution of the water quality indicator due to pollutant discharge into the river system from point sources [8]. The fractional removal levels for different pollutants by different dischargers $\left(\mathrm{x}_{\mathrm{jmn}}^{ \pm}\right)$and goal fulfillment level $\left(\lambda^{ \pm}\right)$are the decision variables in this model, as $c^{ \pm}{ }_{j l}$ in Eq. (5) can be expressed in terms of $x_{j m n}^{ \pm}$using the relation in Eq. (10). For most water quality indicators, a high level of fractional removal of pollutants (e.g., BOD loading, toxic pollutant concentration) results in a low level of water quality indicator (e.g., DO-deficit, nitrate-nitrogen concentration). The lower bound of water quality indicator $\left(c_{j l}^{-}\right)$is therefore expressed in terms of upper bound of fractional removal level $\left(\mathrm{x}^{+}{ }_{\mathrm{jmn}}\right)$ by using Eq. (10).

$c_{j 1}^{-}=f\left(x_{j m n}^{+}\right)$

Similarly, $c_{j 1}^{+}=f\left(x_{j m n}^{-}\right)$

The order of consideration of constraints (5) and (6), along with the selection of bounds of decision variables $\left(\mathrm{x}_{\mathrm{jmn}}^{-}, \mathrm{x}^{+}{ }_{\mathrm{jmn}}, \lambda^{-}\right.$, and $\left.\lambda^{+}\right)$create two different cases of model formulation, which are termed as Case 1 and Case 2, with each problem divided into two submodels. Submodel 1 maximizes the upper bound, $\lambda^{+}$, and Submodel 2 maximizes the lower bound, $\lambda^{-}$. Lower and upper bounds of the decision variables $\left(\mathrm{x}_{j \mathrm{jm}}^{-}\right.$and $\left.\mathrm{x}^{+}{ }_{\mathrm{jmn}}\right)$ are obtained from these two submodels.

\section{Case 1}

The goals of PCA [expressed by constraint (5)] are considered first. In Submodel $1, \lambda^{+}$is maximized, which should be highest resulting from left hand side of the constraint (5). Similar to the goals of PCA, goals of dischargers are expressed, involving the same decision variables $\lambda^{+}$and $\mathrm{x}^{+}{ }_{\mathrm{jmn}}$, as in the expression for goals of PCA. The Submodel 1 is expressed as follows using a linear imprecise membership function:

$\operatorname{Max} \lambda^{+}$

subject to

$$
\begin{array}{ll}
\mathrm{c}_{\mathrm{jl}}^{-} \leq \mathrm{c}_{\mathrm{jl}}^{\mathrm{H}+}-\lambda^{+}\left(\mathrm{c}_{\mathrm{jl}}^{\mathrm{H}-}-\mathrm{c}_{\mathrm{jl}}^{\mathrm{D}+}\right) & \forall \mathrm{j}, \mathrm{l} \\
\mathrm{x}_{\mathrm{jmn}}^{+} \leq \mathrm{x}_{\mathrm{mn}}^{\mathrm{M}+}-\lambda^{+}\left(\mathrm{x}_{\mathrm{mn}}^{\mathrm{M}-}-\mathrm{x}_{\mathrm{mn}}^{\mathrm{L}+}\right) & \forall \mathrm{j}, \mathrm{m}, \mathrm{n} \\
\mathrm{c}_{\mathrm{jl}}^{\mathrm{D}-} \leq \mathrm{c}_{\mathrm{jl}}^{-} \leq \mathrm{c}_{\mathrm{jl}}^{\mathrm{H}+} & \forall \mathrm{j}, \mathrm{l} \\
\mathrm{x}_{\mathrm{mn}}^{\mathrm{L}-} \leq \mathrm{x}_{\mathrm{jmn}}^{+} \leq \mathrm{x}_{\mathrm{mn}}^{\mathrm{M}+} & \forall \mathrm{j}, \mathrm{m}, \mathrm{n} \\
0 \leq \lambda^{+} \leq 1 &
\end{array}
$$


The Submodel 2 is formulated to obtain the lower bound of maximum goal fulfillment level $\left(\lambda^{-}\right)$.

$$
\operatorname{Max} \lambda^{-}
$$

subject to

$$
\begin{array}{ll}
\mathrm{C}_{\mathrm{jl}}^{+} \leq \mathrm{C}_{\mathrm{jl}}^{\mathrm{H}-}-\lambda^{-}\left(\mathrm{C}_{\mathrm{jl}}^{\mathrm{H}+}-\mathrm{C}_{\mathrm{jl}}^{\mathrm{D}-}\right) & \forall \mathrm{j}, \mathrm{l} \\
\mathrm{x}_{\mathrm{jmn}}^{-} \leq \mathrm{x}_{\mathrm{mn}}^{\mathrm{M}-}-\lambda^{-}\left(\mathrm{x}_{\mathrm{mn}}^{\mathrm{M}+}-\mathrm{x}_{\mathrm{mn}}^{\mathrm{L}-}\right) & \forall \mathrm{j}, \mathrm{m}, \mathrm{n} \\
\mathrm{x}_{\mathrm{jmn}}^{-} \leq \mathrm{x}_{\mathrm{jmn} \text { (from submodel 1) }}^{+} & \forall \mathrm{j}, \mathrm{m}, \mathrm{n} \\
\mathrm{C}_{\mathrm{jl}}^{\mathrm{D}-} \leq \mathrm{C}_{\mathrm{jl}}^{+} \leq \mathrm{C}_{\mathrm{jl}}^{\mathrm{H}+} & \forall \mathrm{j}, \mathrm{l} \\
\mathrm{x}_{\mathrm{mn}}^{\mathrm{L}-} \leq \mathrm{x}_{\mathrm{jmn}}^{-} \leq \mathrm{x}_{\mathrm{mn}}^{\mathrm{M}+} & \forall \mathrm{j}, \mathrm{m}, \mathrm{n} \\
0 \leq \lambda^{-} \leq 1 &
\end{array}
$$

As the upper and lower bounds of $\mathrm{x}^{ \pm}{ }_{\mathrm{jmn}}$ are obtained from two different submodels, they are linked by incorporating constraint (22).

Case 2

The constraint based on the goals of dischargers is considered first.

Submodel 1:

$$
\operatorname{Max} \lambda^{+}
$$

subject to

$$
\begin{array}{ll}
\mathrm{x}_{\mathrm{jmn}}^{-} \leq \mathrm{x}_{\mathrm{mn}}^{\mathrm{M}+}-\lambda^{+}\left(\mathrm{x}_{\mathrm{mn}}^{\mathrm{M}-}-\mathrm{x}_{\mathrm{mn}}^{\mathrm{L}+}\right) & \forall \mathrm{j}, \mathrm{m}, \mathrm{n} \\
\mathrm{c}_{\mathrm{jl}}^{+} \leq \mathrm{c}_{\mathrm{jl}}^{\mathrm{H}+}-\lambda^{+}\left(\mathrm{c}_{\mathrm{jl}}^{\mathrm{H}-}-\mathrm{c}_{\mathrm{jl}}^{\mathrm{D}+}\right) & \forall \mathrm{j}, \mathrm{l} \\
\mathrm{x}_{\mathrm{mn}}^{\mathrm{L}-} \leq \mathrm{x}_{\mathrm{jmn}}^{-} \leq \mathrm{x}_{\mathrm{mn}}^{\mathrm{M}+} & \forall \mathrm{j}, \mathrm{m}, \mathrm{n} \\
\mathrm{c}_{\mathrm{jl}}^{\mathrm{D}-} \leq \mathrm{c}_{\mathrm{jl}}^{+} \leq \mathrm{c}_{\mathrm{jl}}^{\mathrm{H}+} & \forall \mathrm{j}, \mathrm{l} \\
0 \leq \lambda^{+} \leq 1 &
\end{array}
$$

Submodel 2:

$\operatorname{Max} \lambda^{-}$

subject to

$$
\begin{array}{ll}
\mathrm{x}_{\mathrm{jmn}}^{+} \leq \mathrm{x}_{\mathrm{mn}}^{\mathrm{M}-}-\lambda^{-}\left(\mathrm{x}_{\mathrm{mn}}^{\mathrm{M}+}-\mathrm{x}_{\mathrm{mn}}^{\mathrm{L}-}\right) & \forall \mathrm{j}, \mathrm{m}, \mathrm{n} \\
\mathrm{C}_{\mathrm{jl}}^{-} \leq \mathrm{C}_{\mathrm{jl}}^{\mathrm{H}-}-\lambda^{-}\left(\mathrm{C}_{\mathrm{jl}}^{\mathrm{H}+}-\mathrm{c}_{\mathrm{jl}}^{\mathrm{D}-}\right) & \forall \mathrm{j}, \mathrm{l} \\
\mathrm{x}_{\mathrm{jmn}}^{+} \geq \mathrm{x}_{\mathrm{jmn} \text { (from submodel 1) }}^{-} & \forall \mathrm{j}, \mathrm{m}, \mathrm{n} \\
\mathrm{x}_{\mathrm{mn}}^{\mathrm{L}-} \leq \mathrm{x}_{\mathrm{jmn}}^{+} \leq \mathrm{x}_{\mathrm{mn}}^{\mathrm{M}+} & \forall \mathrm{j}, \mathrm{m}, \mathrm{n} \\
\mathrm{C}_{\mathrm{jl}}^{\mathrm{D}-} \leq \mathrm{c}_{\mathrm{jl}}^{-} \leq \mathrm{c}_{\mathrm{jl}}^{\mathrm{H}+} & \forall \mathrm{j}, \mathrm{l} \\
0 \leq \lambda^{-} \leq 1 &
\end{array}
$$




\section{MODEL APPLICATION}

The model is applied to a hypothetical river system shown in Figure 1. The water quality indicator of interest is the DO-deficit at 18 number of checkpoints in the river system due to the point sources of BOD. The saturation DO concentration is taken as $10 \mathrm{mg} / \mathrm{L}$ for all the reaches. A deterministic value of river flow as 7 Mcum/day is considered. The details of the effluent flow and imprecise membership functions are given in Table 1 and 2, respectively.

Figure 1. A hypothetical river system.

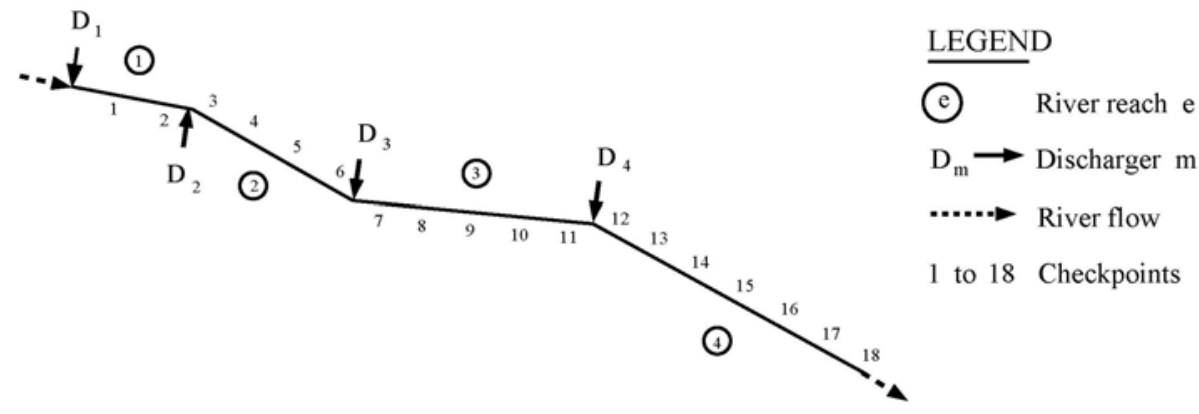

Table 1. Effluent flow data [8].

\begin{tabular}{|c|c|c|c|}
\hline Discharger & $\begin{array}{c}\text { Effluent Flow Rate } \\
\left(10^{4} \mathrm{~m}^{3} / \mathrm{day}\right)\end{array}$ & $\begin{array}{c}\text { BOD Concentration } \\
(\mathrm{mg} / \mathrm{L})\end{array}$ & $\begin{array}{c}\text { DO Concentration } \\
(\mathrm{mg} / \mathrm{L})\end{array}$ \\
\hline $\mathrm{D}_{1}$ & 2.134 & 1250 & 1.230 \\
$\mathrm{D}_{2}$ & 6.321 & 1415 & 2.400 \\
$\mathrm{D}_{3}$ & 7.554 & 1040 & 1.700 \\
$\mathrm{D}_{4}$ & 5.180 & 935 & 2.160 \\
\hline
\end{tabular}

Table 2. Details of imprecise membership functions.

\begin{tabular}{|c|c|c|c|c|c|}
\hline \multirow{2}{*}{$\begin{array}{l}\text { River } \\
\text { Reach }\end{array}$} & \multirow{2}{*}{$\begin{array}{l}\text { Check- } \\
\text { points }\end{array}$} & $\mathrm{C}^{\mathrm{D}}{ }_{\mathrm{l}}(\mathrm{mg} / \mathrm{L})$ & $\mathrm{c}^{\mathrm{H}}{ }_{1}(\mathrm{mg} / \mathrm{L})$ & $\mathrm{X}_{\mathrm{m}}^{\mathrm{L}}$ & $\mathrm{x}_{\mathrm{m}}^{\mathrm{M}}$ \\
\hline & & + & + & + & + \\
\hline \multirow[b]{2}{*}{$\mathrm{R}_{1}$} & \multirow[b]{2}{*}{$1-2$} & $(0.00)$ & $(3.00)$ & $(0.30)$ & $(0.85)$ \\
\hline & & $0.00 \quad 0.00$ & $2.70 \quad 3.20$ & $0.25 \quad 0.35$ & 0.80 \\
\hline \multirow{2}{*}{$\mathrm{R}_{2}$} & \multirow{2}{*}{$3-6$} & $(0.10)$ & (3.00) & $(0.30)$ & \multirow{2}{*}{ (0.85) } \\
\hline & & $0.00 \quad 0.10$ & $2.70 \quad 3.20$ & $0.25 \quad 0.35$ & \\
\hline \multirow{2}{*}{$\mathrm{R}_{3}$} & \multirow{2}{*}{$7-11$} & $(0.20)$ & (3.50) & $(0.35)$ & $(0.85)$ \\
\hline & & $0.17 \quad 0.22$ & 3.30 & $0.30 \quad 0.40$ & 0.80 \\
\hline \multirow{2}{*}{$\mathrm{R}_{4}$} & \multirow{2}{*}{$12-18$} & $(0.20)$ & (3.50) & $(0.35)$ & $(0.85)$ \\
\hline & & 0.17 & 3.30 & $0.30 \quad 0.40$ & 0.80 \\
\hline
\end{tabular}

( ) : Deterministic case, ‘-' : Lower bound, ‘+' : Upper bound 


\section{RESULTS AND DISCUSSION}

The results obtained from the model facilitate a comparison between the deterministic case, where the membership parameters are deterministic numbers, and the grey uncertain case, where the membership parameters are uncertain, and are represented as interval grey numbers. The results of the analysis are summarized in Table 3, give a set of

Table 3. Details of fractional removal levels obtained from GFWLAM.

\begin{tabular}{|c|c|c|c|c|c|c|}
\hline \multirow{2}{*}{ Type } & \multirow{2}{*}{$\begin{array}{c}\text { Gd () of } \\
\text { Inputs (\%)* }\end{array}$} & \multicolumn{3}{|c|}{ Solutions } & \multicolumn{2}{|c|}{ Gd () of Outputs (\%) } \\
\hline & & $\lambda^{-}$ & $\lambda^{+}$ & $\mathrm{x}^{ \pm}{ }_{1}$ to $\mathrm{x}^{ \pm}{ }_{4}$ & $\lambda^{ \pm}$ & Avg. $\mathrm{X}^{ \pm} *$ \\
\hline 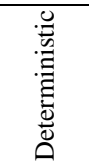 & 0.000 & 0.4277 & 0.4277 & $\begin{array}{l}{[0.615,0.615]} \\
{[0.615,0.615]} \\
{[0.636,0.636]} \\
{[0.636,0.636]}\end{array}$ & 0.000 & 0.000 \\
\hline 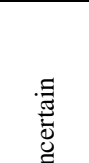 & 31.304 & $\begin{array}{c}\underline{\text { Case1 }} \\
0.3126\end{array}$ & 0.5745 & $\begin{array}{l}{[0.597,0.641]} \\
{[0.597,0.641]} \\
{[0.612,0.670]} \\
{[0.612,0.670]}\end{array}$ & 59.033 & 8.115 \\
\hline 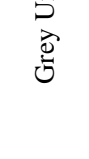 & & $\begin{array}{l}\underline{\text { Case2 }} \\
0.2163\end{array}$ & 0.5745 & $\begin{array}{l}{[0.641,0.641]} \\
{[0.641,0.641]} \\
{[0.670,0.670]} \\
{[0.670,0.670]}\end{array}$ & 90.584 & 0.000 \\
\hline
\end{tabular}

(*) : Average values, Gd ( ) : Grey Degree [4]

flexible policies (optimal fractional removal levels, $\mathrm{X}^{* \pm}$, of different pollutants for different dischargers) in the form of interval grey numbers for optimal values of $\lambda^{ \pm}$, which is also an interval grey number. Table 3 shows the optimal fractional removal levels of the pollutants by different dischargers for both deterministic case and grey uncertain case. For a particular set of membership parameters (Table 2) a set of optimal values of decision variables are derived for both Case 1 and Case 2. To evaluate the quality of input or output uncertain information, a measure of "Grey degree" is used [4]. The expression for grey degree of interval grey number $\left(\mathrm{x}^{ \pm}\right)$is $\operatorname{Gd}\left(\mathrm{x}^{ \pm}\right)=\left(\mathrm{x}_{\omega} / \mathrm{x}_{\mathrm{m}}\right) \times 100 \%$, where $x_{m}=1 / 2\left[x^{-}+x^{+}\right]$, and $x_{\omega}=\left[x^{+}-x^{-}\right]$. As the grey degree of optimal value of objective function decreases, the effectiveness of the grey model increases with decreasing system uncertainties. Therefore, a lower value of grey degree of objective function implies the achievement of a more applicable and reliable grey solutions. For example, in Case 1 of Table 3, $\lambda^{ \pm}=[0.3126,0.5745]$; where $\lambda^{-}=0.3126 ; \lambda^{+}=0.5745$; whitened mid value, $\lambda_{\mathrm{m}}=0.4436$; and width, $\lambda_{\omega}=0.2619$; this results in a grey degree of $\lambda^{ \pm}, \operatorname{Gd}\left(\lambda^{ \pm}\right)=(0.2619 / 0.4436)=0.5903$, i.e., $59.03 \%$. In Case 1 grey degree of $\lambda^{ \pm}$is less than the grey degree of $\lambda^{ \pm}$obtained in Case 2, indicating that Case 1 describes more appropriate imprecise fuzzy decision in this particular problem. The value of $\lambda^{ \pm}$in deterministic case 0.4277 lies in this closed interval [0.3126, 0.5745]. 
A sensitivity analysis to examine the variation of width of grey output variables with grey input variables for different values of river flow is also carried out but is not presented here.

\section{CONCLUSIONS}

In the present work, uncertainty associated with fuzzy membership functions for a water quality management problem is addressed through interval grey numbers. A grey fuzzy optimization model for water quality management of a river system is developed. Application of the optimization model with imprecise membership functions is illustrated with a hypothetical river system. The model application is demonstrated with a hypothetical example.

\section{REFERENCES}

[1] Sasikumar K. and Mujumdar P. P., "Fuzzy optimization model for water quality management of a river system”, J. Water Resour. Plann. Manage. Div., Am. Soc. Civ. Eng., 124, (1998), pp 79-88.

[2] Liu S. and Lin Y., "An introduction to grey systems: foundation, methodology and applications", $1^{\text {st }}$ edition, IIGSS Academic Pub., P.A., (1998).

[3] Moore R. E., "Methods and applications of interval analysis", SIAM, Philadelphia, (1979).

[4] Huang G. H., Baetz B. W. and Patry G. G., "A grey integer programming approach for waste management planning”, Eur. J. Oper. Res., 83, (1995), pp 594-620.

[5] Karmakar S. and Mujumdar P. P., "Grey fuzzy optimization model for water quality management of a river system”, Fuzzy Sets and Systems, (2003), (Communicated).

[6] Ishibuchi H. and Tanaka H., "Multiobjective programming in optimization of the interval objective function”, Eur. J. Oper. Res., 48, (1990), pp 219-225.

[7] Bellman R. E. and Zadeh L. A., "Decision-making in a fuzzy environment", Mgmt. Sci., 17(4), (1970), pp B141-B164.

[8] Mujumdar P. P. and Sasikumar K., “A fuzzy risk approach for seasonal water quality management of a river system”, Water Resour. Res., 38(1), (2002), 10.1029/2000WR000126, pp 5-1 - 5-9. 